\title{
SYMBOL AND ITS EVOLUTION
}

\author{
ERKKI LUUK \\ erkkil@gmail.com \\ Institute of Computer Science, University of Tartu, Estonia
}

\begin{abstract}
The paper investigates the problem of tracing the emergence of symbolism in the Homo lineage. We define the symbol via the notions of arbitrary and spatiotemporally displaced reference, and analyze the earliest manifestations of different forms of symbolism: color, figurative, abstract (in the form of codes, other signs, and ritual burials), and (proto)language. Besides symbols themselves, diverse physical and behavioral traits that might constitute a circumstantial evidence for symbolism are scrutinized. Drawing on archaeological and fossil evidence, a plausible time for the emergence of symbol in protolanguage is estimated to be $850 \ldots 2200$ kya.
\end{abstract}

\section{Symbol}

\subsection{Introduction}

Symbolism is almost universally viewed as a distinctively (frequently even exclusively) human trait, and one that is fundamental to human language. Owing to the multi-faceted nature of symbol (more of which below), the scarcity of direct evidence of symbolism from Middle and Lower Paleolithic (c. 50 ... 300 and $300 \ldots$ 3300 kya, respectively), and the uncertainty of circumstantial evidence from rare fossil and (even rarer) archaeological finds that might imply symbolism, tracing its emergence in the human lineage is a complex task.

\subsection{Definition}

As 'symbol' is a pretheoretic term, it has to be defined from the outset. Two features that are usually, if not implicitly, held to be characteristic of 'symbol' are the arbitrary nature of reference (a non-necessary link between a sign and its meaning) and a used potential for spatiotemporally displaced reference ${ }^{1}$. Arbi-

\footnotetext{
Abbreviations: kya - thousand years ago.

${ }^{1}$ The above definition of symbol opens the possibility that, in natural communication, symbolism is uniquely human. For example, while bottlenose dolphins' signature whistles are arbitrary, the whistles' natural potential for spatiotemporally displaced reference is not evident, as each dolphin uses its own distinctive signature whistle (Janik, Sayigh, \& Wells, 2006). Although dolphins frequently copy each other signature whistles in the wild, it is not clear whether this qualifies as a reference to third person individuals (which would indicate a used potential for spatiotemporally displaced reference).
} 
trariness is closely related to the number of signs (the more signs the greater the pressure for their arbitrariness). In the form of grammaticalization, the prevailing drift of natural languages towards arbitrariness is evident both on historical and evolutionary scales (Heine \& Kuteva, 2007).

Differently from symbols, 'index' and 'icon' are defined by a necessary and natural link between a sign and its meaning. In icons, the link is based on similarity. In indices, it is based on any other necessary relation (e.g. cause-effect or whole-part relation). In practice, various degrees of iconicity as possible, and symbols (e.g. the Christian cross, or onomatopoetic words like knock, bump, crash) may exhibit iconicity as well (Luuk, 2013). Equipped with these definitions, one notices that the word 'symbol' gets colloquially used in very different senses. For example, status symbols (e.g. expensive clothes) have not much in common with linguistic symbols (e.g. words). By the above definitions, only the latter are symbols. The former are indices of wealth and, more generally, success. Although the difference might seem minor, it has fundamental implications on the archaeological evidence for symbolism. For example, one cannot infer symbolism (and by extension, language) from personal ornaments, as the most parsimonious interpretation of personal ornaments is that they are status symbols (Sterelny, 2008).

\section{Ornamental symbolism}

As personal ornaments are costly, their are indices of success. This observation is archaeologically supported by the fact that most preserved ${ }^{2}$ objects used in Pleistocene pendants (e.g. predator teeth and suitable seashells) are hard to come by. As killing a predator is evolutionarily extremely costly, it is a bona fide indicator of success. Nevertheless, it is exceedingly common to interpret personal ornaments (and to a lesser extent pigment use) as manifestations of symbolism (e.g. Bednarik, 2008b; Chase, 1994; d'Errico et al., 2003; d'Errico \& Backwell, 2016; Langley, O'Connor, \& Piotto, 2016). Observe also that personal ornaments do not imply displaced reference, as they bestow status only to their wearers. Thus, personal ornaments per se are not indicators of symbolism (and, by extension, language). Of course, an indexical function does not preclude a symbolic one (and objects can be clearly symbolic as well - we will see some examples below) but non-symbolism should be the null hypothesis for objects with an indexical function.

However, even non-symbolic objects may belong to a behavioral pattern, some other parts of which are indicative of symbolism. For example, a procurement and processing of beads, pendants or colorants for using them in body or garment ornamentation puts up a much stronger case for symbolism than the (processed)

\footnotetext{
${ }^{2}$ Some well-preserved Holocene burials have contained personal ornaments of perishable materials, e.g. seeds beads (Tryon \& Faith, 2013).
} 
objects themselves. The evidence gets stronger if the nearest source for the objects lies at least several kilometres from the place they were processed and/or applied. Of course, the evidence is circumstantial, but it constitutes a much stronger case for symbolism than when possibly non-symbolic objects are just claimed to be symbols.

\section{Color symbolism}

The earliest evidence of colorant processing - ochre on grindstones - is from the Kapthurin formation in Kenya (284 ... 500 kya, Tryon \& Faith, 2013). In general, it is very difficult to rule out all potential utilitarian uses for Middle and Lower Paleolithic colorant finds (medicine, hide preservative, protection from sun and insects, camouflage, startling of prey and conspecifics, the preparation of mastics for hafting, etc. - Barham, 2002; Sterelny, 2008; Wadley, 2001; Wadley, Williamson, \& Lombard, 2004) but even where this could be done, there remains the possibility that pigment was used because definitive colors were preferred for aesthetic or cognitive (salience) reasons. Even non-human species differentiate between aesthetic and non-aesthetic stimuli and utilize definitive colors as behavioral cues (Watanabe, 2010) and so do children in their first year (Baldwin, 2006). While coloring is probably uniquely human, there is nothing inherently symbolic about it. For color symbolism to be present, a non-natural, non-random and nonavailability-specific link between color and object (or color and figure) has to be evidenced. For example, a brown, black or white foot figure on a cave wall is probably color iconism (reference by similarity), one purple foot figure is probably a chance but ten purple foot figures suggest color symbolism (except if purple was one of the few pigments available to the artist and the others were equally non-iconic, e.g. crimson and green). Thus, extremely specific configurations of archeological and geological evidence are required to attest color symbolism.

\section{Figurative symbolism}

Figurative symbolism is generally easier to establish. Importantly, as figurative paintings and sculptures are at least partly iconic, representational art per se does not entail symbolism (Luuk, 2013). Thus, the vast majority of cave paintings and early sculptures (including the Berekhat Ram figurine from $250 \mathrm{kya}$ - d'Errico et al., 2003) have to be excluded from possible indicators of symbolism. However, some early examples of figurative symbolism remain. For example, the two half-lion/half-man figurines from 31 kya (Conard, 2003) are symbolic, as they exhibit both spatiotemporally displaced and arbitrary reference (spatiotemporally displaced, because a half-lion/half-man has hardly any potential to refer to anything here and now, and arbitrary because the figurines are not representational as wholes). By extension, the figurines are reasonable proxies for language (or at least protolanguage). A similar case could be made about the Hohle Fels fe- 
male figurine (Conard, 2009), which, however, would be better analyzed in the following section.

\section{Abstract symbolism}

In abstract symbolism, an important distinction is between codes and elementary abstract signs. Only the former can be compositional. The codes may represent calendars, bookkeeping tables, written texts, etc. Another difference is that codes are clearly symbolic (with elementary abstract signs this may not be so clear).

\subsection{Codes}

Very few examples of codes from (Upper) Paleolithic have been found ${ }^{3}$. One of the first examples of complex code appears on the La Marche antler from 16 kya (d'Errico, 1995). Simple codes are probably in evidence since at least the Ishango bone from c. 20 kya (Bogoshi, Naidoo, \& Webb, 1987; Brooks \& Smith, 1987). No preserved examples of codes from Lower and Middle Paleolithic are known.

\subsection{Signs}

The majority of putative abstract "signs" from Middle and Lower Paleolithic fall into a category of 'abstract art' for which doodling is a more parsimonious explanation than symbolism (Bednarik, 1995a; Halverson, 1995). For example, Bednarik's (1995a) paper on concept-mediated marking in Lower Paleolithic makes no allegations as to the symbolicity or even intentionality of the markings. The markings that he analyzed were abstract, and some of them were very similar to those Middle Paleolithic markings found on bone and ochre pieces from Blombos Cave that are claimed to be "irrefutable evidence of symbolic behavior" (d'Errico et al., 2003, p. 4). The claim relies, of course, on a pretheoretic notion of symbol. However, some early examples of abstract symbolism remain.

Markings on the above-mentioned ivory female figurine from Hohle Fels, Germany, dated to the Aurignacian 35 kya, have been interpreted as ideograms representing the Upper Paleolithic Double Goddess (Harrod, 2011). While the interpretation may seem dubious, the distorted and geometrically decorated figurine is very likely symbolic.

An impressive collection of abstract signs have been discovered in Chauvet cave in France (Petzinger \& Nowell, 2014), the earliest of which are dated to 35 ... 38.5 kya (early Upper Paleolithic). The number (17) of distinctive non-figurative signs at Chauvet is striking. However, by being scattered spatially (and likely also temporally), they do not form a code any more than other abstract art styles do. Nevertheless, the signs' abstract (albeit half-iconic - cruciform, reniform,

\footnotetext{
${ }^{3}$ None of them is definitely deciphred.
} 
negative and positive hand, etc.) nature more or less qualifies them as symbols, even though one has no idea what they stood for.

Crossing over to Middle Paleolithic, a tradition of engraving ostrich egg shells, dated to 60 kya, has been discovered in South Africa (Texier et al., 2010). The fixed, abstract and persistent nature of the engravings qualifies them as symbols of (at least) group identity. No doubt to the late engravers the hatched band motive they reproduced for millenia seemed rather pregiven than 'arbitrary' (in another but a related meaning of the word). In addition, for those who started the tradition, the engravings may have been iconic (e.g. of a spun rope). However, the tradition's length ensures that they became abstract, symbolic and arbitrary (in the definitive meaning).

In general, cupules are better candidates for symbols than other forms of 'abstract art' because their manufacture is labor intensive, which rules out doodling as well as coincidental configurations of cut marks (Bednarik, 1995b, 2008a, 2008b). At the same time, it is plausible that some cupules (at least those on horizontal surfaces) were used as containers or were unintentional byproducts of other functional activities (e.g. grinding). Although a functional role does not preclude a symbolic use, it makes cupules' status as an evidence of symbolism ambiguous. Nevertheless, cupules are seemingly a later addition to hominins' behavioral repertoire than personal ornaments (at least 150 and 300 kya, respectively - Bednarik, 2008a, 2008b).

\subsection{Burials}

Although emotional attachment is a more parsimonious explanation for burials than symbolism (Sterelny, 2008), grave goods, structures and their configurations can point to symbolism as well. A Neanderthal burial site, La Ferrassie, dated to 65-70 kya, suggests a possible symbolic activity (Zilhão et al., 2010; Bednarik, 1995a, 2008a). The find that was perhaps the most implicative of symbolism in La Ferrassie was a limestone slab with 18 cupules (16 of which were arranged in pairs), covering a child's corpse (Bednarik, 2008a, citing Peyroni, 1934). The earliest modern human burial, dated to $74 \mathrm{kya}$, has been recently excavated in Border Cave in South Africa. The burial was associated with personal ornaments (perforated Conus shells — d'Errico \& Backwell, 2016).

\subsection{Language}

By far the oldest evidence for symbolism we have is circumstantial and, ironically, it is an evidence for language, the most elusive form of symbolism archaeologically. But first, some qualifications. We are interested in the time the language evolved. By "language" we mean (proto)language, i.e. a language which could be a protolanguage. A rough definition of protolanguage would be "a human language with a nonmodern syntax". A precise one could be "a human language without cases and adpositions". The function of cases and adpositions is to mark 
arguments of the head of the sentence. The sentence is a precondition of any syntax, modern or nonmodern. In modern languages, the head of the sentence is usually a finite verb or flexible ${ }^{4}$. As no modern languages without cases or adpositions are attested" ${ }^{5}$, they are a suitable dividing line. By the "time language evolved" we mean the time it emerged. Johanssen (2005) constrained this time to between 500 and $5000 \mathrm{kya}$, which is the necessary period the language had to emerge. We are interested in refining it, i.e. in a both necessary and plausible (with more than 0.5 probability) timeline of the evolution of language.

\subsubsection{Evidence from colonization}

It is well known that Homo erectus ${ }^{6}$ crossed at least $19 \mathrm{~km}$ of open sea to colonize Flores c. 850 kya or earlier (Gibbons, 1998a; Morwood, O’Sullivan, Aziz, $\&$ Raza, 1998). It has been (plausibly) argued that watercraft manufacture and navigation entail a level of communication that would be unattainable without a (proto)language. Although rafting on flotsam is a possibility (Gibbons, 1998a), it is not a likely one, given $H$. erectus's ability to manufacture mode 2 tools and successful colonization of much of the Old World (from Africa and Western Europe to Java, China and, possibly, Central Siberia - Ascenzi, Benvenuti, \& Segre, 1997; Asfaw et al., 2002; Bar-Yosef \& Belfer-Cohen, 2001; Gibbons, 1998b; Larick et al., 2001; Waters, Forman, \& Pierson, 1997).

For taphonomic reasons, a direct evidence of symbolic activity in so distant times would be a find of centuries. Likewise, the colonization of the southern arc by modern humans much later (likely 65 ... 90 kya - Clarkson et al., 2017) provides clear evidence of symbolic conceptualization but very few symbols before the colonizers arrived in Australia (Balme, Davidson, McDonald, Stern, \& Veth, 2009). Even more surprisingly, there is a higher proportion of sites with symbols early in Australia's colonization rather than later (Balme et al., 2009).

\subsubsection{Anatomical evidence}

As compared to other extinct hominids, medium and late $H$. erectus (less than $1600 \mathrm{kya}$ ) had an increase in thoracic innervation, similar to that of modern humans and H. Neanderthalis (MacLarnon \& Hewitt, 1999; Meyer, Lordkipanidze, $\&$ Vekua, 2006). The authors associate it with an enhanced breathing control, which most likely evolved to facilitate speech (MacLarnon \& Hewitt, 1999). Fitch (2000) notes that it is difficult to know whether increased respiratory control directly involved speech, or evolved for other reasons (e.g. prolonged running or

\footnotetext{
${ }^{4}$ There is no general agreement as to whether 'verb' is in fact universal in modern languages (or how to define it — Himmelmann, 2007; Luuk, 2010).

${ }^{5}$ Pidgins, which are not full blown languages, are a possible exception.

${ }^{6}$ For simplicity, I assume the null hypothesis (proposed by Lordkipanidze et al., 2013) that $H$. habilis, $H$. ergaster and $H$. rudolfensis belong to a single evolving lineage of $H$. erectus.
} 
swimming), and provided only a necessary preadaptation to speech. There is another aspect to this argument. By "speech" is meant modern speech, but no-one assumes that $H$. erectus was capable of that. By definition, a more modest range of vocalization that could support protolanguage would have been sufficient for its production.

An anatomical difference that allows humans to produce a wider range of formant patterns than other mammals is a lowered larynx (Lieberman, Klatt, \& Wilson, 1969). Lieberman (1987) suggests that the lowering of larynx started with H. erectus $^{7}$. Since the decent of larynx has an evolutionary cost (vulnerability to choking - Fitch, 2000), there must have been a selective pressure for the descent. In addition, to bestow a phonetic advantage, larynx must be significantly lower than its position in extant nonhuman apes (Fitch, 2000). At least two adaptive scenarios explain the presumably gradual descent of the larynx in Homo: facilitating mouth breathing during extreme physical challenge (Lieberman, 1987) and displays of exaggerated power ${ }^{8}$ to intimidate enemies and competitors and attract potential mates (Ohala, 1984). Both scenarios might result in the descent of larynx as a preadaptation to speech.

\subsubsection{Conclusion}

Three independent and converging pieces of evidence $(1,2,3)$ :

1. H. erectus' colonization of Flores and much of the other Old World (Gibbons, 1998a; Morwood et al., 1998; Ascenzi et al., 1997; Asfaw et al., 2002; Bar-Yosef \& Belfer-Cohen, 2001; Gibbons, 1998b; Larick et al., 2001; Waters et al., 1997),

2. H. erectus' enhanced respiratory control (MacLarnon \& Hewitt, 1999; Meyer et al., 2006),

3. A lowering of larynx in H. erectus (Lieberman, 1987),

4. An enhanced capacity for vocalizations in $H$. erectus $(2,3)$,

5. An enhanced capacity for vocal communication in H. erectus (4),

point to some kind of language in $H$. erectus prior to its colonization of Flores. Of course, the evidence is circumstantial but this is always the case in language evolution - the earliest direct evidence for language (an inscription on a wooden tablet - Whitley, 2003) is from less than 10 kya.

\footnotetext{
${ }^{7}$ Larynx does not fossilize, so its position can only be conjectured from fossiles (and reliable clues are lacking — Fitch, 2000).

${ }^{8} \mathrm{~A}$ lowered larynx allows to imitate vocalizations of larger animals that lack this feature (Fitch, 2000).
} 
As Homo habilis, the first known Homo species (with the earliest occurrence c. 2300 kya - Spoor et al., 2007), was not scrutinized by MacLarnon and Hewitt (1999), it is possible that this species, too, was capable of enhanced vocalizations. According to Tobias (1998), evidence from endocranial casts suggests that $H$. habilis was a "speaker"9. When combined, the archaeological and anatomical evidence indicate that $H$. erectus (possibly even starting from $H$. habilis) used some kind of (proto)language, the emergence of which could be tentatively bracketed between 850 and 2200 kya. At present, this constitutes the earliest plausible evidence of symbolism. As mentioned above, the time when language evolved was previously constrained to 500 ... 5000 kya (Johansson, 2006).

\section{Conclusion}

In this paper we have (1) defined the symbol, (2) analyzed some possible proxies of symbolism, and (3) reconstructed a plausible timeline for the emergence of symbol (viz., in protolanguage) by drawing on relevant fossil and archaeological evidence. We have bracketed the plausible time of the emergence of symbol to 850 ... 2200 kya. Symbol is defined by its two distinctive features: (a) an arbitrary nature (a non-necessary link between a sign and its meaning), and (b) a used potential for spatiotemporally displaced reference. The traits we have analyzed include behavioral patterns (e.g. coloring and engraving traditions associated with procurement and processing of materials, watercraft manufacture and navigation, ritual burials associated with personal ornaments, etc.) and anatomical features like thoracic innervation and the position of larynx. To a different degree, all these features can be viewed as proxies for symbolism. Without a doubt, an engraving tradition makes a much better proxy for symbolism than an extinct species' (possibly) lowered larynx, but it is also a much more recent one (on the order of 100 and 1000 kya, respectively). For taphonomic reasons, fossil evidence dominates the $>500$ kya era over the archaeological, thus being the main window to the behavioral capacities of the hominids of the period.

\section{Acknowledgements}

This work has been supported by IUT20-56 and European Regional Development Fund through CEES.

\footnotetext{
${ }^{9}$ It has been also proposed that language originated in gestural modality (Corballis, 2010). This is supported by the observation that our closest extant relatives are proficient in gestural but poor at vocal imitation (Pika \& Mitani, 2006). If the scenario is true, the emergence of language might have predated a selection for enhanced vocalizations. We have not considered this possibility in reconstructing the present timeline.
} 


\section{References}

Ascenzi, A., Benvenuti, A., \& Segre, A. G. (1997). On the paleopathologic findings exhibited by the late Homo erectus of Ceprano, Italy. Human Evolution, 12(3), 189-196.

Asfaw, B., Gilbert, W. H., Beyene, Y., Hart, W. K., Renne, P. R., WoldeGabriel, G., Vrba, E. S., \& White, T. D. (2002). Remains of Homo erectus from Bouri, Middle Awash, Ethiopia. Nature, 416, 317-320.

Baldwin, J. M. (2006). Handbook Of Psychology: Senses And Intellect (2nd [orig. 1890] ed.). Whitefish, MT: Kessinger Publishing.

Balme, J., Davidson, I., McDonald, J., Stern, N., \& Veth, P. (2009). Symbolic behaviour and the peopling of the southern arc route to Australia. Quaternary International, 202(1), 59 - 68. (Great Arc of Human Dispersal)

Barham, L. S. (2002). Systematic pigment use in the Middle Pleistocene of South-Central Africa. Current Anthropology, 43(1), 181-190.

Bar-Yosef, O., \& Belfer-Cohen, A. (2001). From Africa to Eurasia - early dispersals. Quaternary International, 75(1), 19-28.

Bednarik, R. G. (1995a). Concept-mediated marking in the Lower Palaeolithic. Current Anthropology, 36(4), 605-616.

Bednarik, R. G. (1995b). Reply to comments on Bednarik's "Concept-mediated marking in the Lower Palaeolithic". Current Anthropology, 36(4), 626-630.

Bednarik, R. G. (2008a). Cupules. Rock Art Research, 25(1), 61-100.

Bednarik, R. G. (2008b). The origins of symboling. Signs, 2, 82-113.

Bogoshi, J., Naidoo, K., \& Webb, J. (1987). The oldest mathematical artifact. Mathematical Gazette, 71, 458.

Brooks, A. S., \& Smith, C. C. (1987). Ishango revisited: new age determinations and cultural interpretations. African Archaeological Review, 5(1), 65-78.

Chase, P. G. (1994). On symbols and the Palaeolithic. Current Anthropology, 35(5), 627-629.

Clarkson, C., Jacobs, Z., Marwick, B., Fullagar, R., Wallis, L., Smith, M., Roberts, R. G., Hayes, E., Lowe, K., Carah, X., Florin, S. A., McNeil, J., Cox, D., Arnold, L. J., Hua, Q., Huntley, J., Brand, H. E. A., Manne, T., Fairbairn, A., Shulmeister, J., Lyle, L., Salinas, M., Page, M., Connell, K., Park, G., Norman, K., Murphy, T., \& Pardoe, C. (2017). Human occupation of northern Australia by 65,000 years ago. Nature, 547(7663), 306-310.

Conard, N. J. (2003). Palaeolithic ivory sculptures from southwestern Germany and the origins of figurative art. Nature, 426, 830-832.

Conard, N. J. (2009). A female figurine from the basal Aurignacian of Hohle Fels Cave in southwestern Germany. Nature, 459(7244), 248-252.

Corballis, M. C. (2010). The gestural origins of language. Wiley Interdisciplinary Reviews: Cognitive Science, 1(1), 2-7.

d'Errico, F. (1995). A new model and its implications for the origin of writing: 
La Marche antler revisited. Cambridge Archaeological Journal, 5(2), 163206.

d'Errico, F., \& Backwell, L. (2016). Earliest evidence of personal ornaments associated with burial: The Conus shells from Border Cave. Journal of Human Evolution, 93(Supplement C), 91 - 108.

d'Errico, F., Henshilwood, C., Lawson, G., Vanhaeren, M., Tillier, A.-M., Soressi, M., Bresson, F., Maureille, B., Nowell, A., Lakarra, J., Backwell, L., \& Julien, M. (2003). Archaeological evidence for the emergence of language, symbolism, and music an alternative multidisciplinary perspective. Journal of World Prehistory, 17(1), 1-70.

Fitch, W. T. (2000). Vocal production in nonhuman mammals: implications for the evolution of speech. In Evolution of Language Conference. Paris.

Gibbons, A. (1998a). Ancient island tools suggest Homo erectus was a seafarer. Science, 279(5357), 1635-1637.

Gibbons, A. (1998b). In China, a handier Homo erectus. Science, 279(5357), 1636.

Halverson, J. (1995). Comment on Bednarik's "Concept-mediated marking in the Lower Palaeolithic". Current Anthropology, 36(4), 621.

Harrod, J. B. (2011). The Hohle Fels female figurine: Not pornography but a representation of the Upper Paleolithic Double Goddess. Journal of Archaeomythology, 7, 204-218.

Heine, B., \& Kuteva, T. (2007). The genesis of grammar: a reconstruction. New York: Oxford University Press.

Himmelmann, N. P. (2007). Lexical categories and voice in Tagalog. In P. Austin \& S. Musgrave (Eds.), Voice and Grammatical Functions in Austronesian Languages. Stanford: CSLI.

Janik, V. M., Sayigh, L. S., \& Wells, R. S. (2006). Signature whistle shape conveys identity information to bottlenose dolphins. Proceedings of the National Academy of Sciences of the United States of America, 103(21), 8293-7. (Journal Article Research Support, Non-U.S. Gov't Research Support, U.S. Gov't, Non-P.H.S.)

Johansson, S. (2006). Constraining the time when language evolved. In A. Cangelosi, A. D. M. Smith, \& K. Smith (Eds.), The Evolution of Language: Proceedings of the 6th International Conference (EVOLANG6) (pp. 152159). Singapore: World Scientific.

Langley, M. C., O'Connor, S., \& Piotto, E. (2016). 42,000-year-old worked and pigment-stained Nautilus shell from Jerimalai (Timor-Leste): Evidence for an early coastal adaptation in ISEA. Journal of Human Evolution, 97(Supplement C), 1 - 16.

Larick, R., Ciochon, R. L., Zaim, Y., Sudijono, Suminto, Rizal, Y., Aziz, F., Reagan, M., \& Heizler, M. (2001). Early Pleistocene 40ar/39ar ages for Bapang Formation hominins, Central Jawa, Indonesia. Proceedings of the National 
Academy of Sciences of the United States of America, 98(9), 4866-4871.

Lieberman, P. I. (1987). The Biology and Evolution of Language (2nd [orig. 1984] ed.). Harvard University Press.

Lieberman, P. I., Klatt, D. H., \& Wilson, W. A. (1969). Vocal tract limitations on the vowel repertoires of rhesus monkey and other nonhuman primates. The Journal of the Acoustical Society of America, 46(1A), 97-97.

Lordkipanidze, D., León, M. S. Ponce de, Margvelashvili, A., Rak, Y., Rightmire, G. P., Vekua, A., \& Zollikofer, C. P. E. (2013). A complete skull from Dmanisi, Georgia, and the evolutionary biology of early Homo. Science, 342(6156), 326-331.

Luuk, E. (2010). Nouns, verbs and flexibles: implications for typologies of word classes. Language Sciences, 32(3), 349-365.

Luuk, E. (2013). The structure and evolution of symbol. New Ideas in Psychology, 31, 87-97.

MacLarnon, A. M., \& Hewitt, G. P. (1999). The evolution of human speech: The role of enhanced breathing control. American Journal of Physical Anthropology, 109, 341-363.

Meyer, M. R., Lordkipanidze, D., \& Vekua, A. (2006). Evidence for the anatomical capacity for spoken language in Homo erectus. American Journal of Physical Anthropology Supplement, 42, 130.

Morwood, M. J., O’Sullivan, P. B., Aziz, F., \& Raza, A. (1998). Fission-track ages of stone tools and fossils on the east Indonesian island of Flores. Nature, $392,173-176$.

Ohala, J. J. (1984). An ethological perspective on common cross-language utilization of F0 of voice. Phonetica, 41(1), 1-16.

Petzinger, G. von, \& Nowell, A. (2014). A place in time: Situating Chauvet within the long chronology of symbolic behavioral development. Journal of Human Evolution, 74, 37 - 54.

Peyroni, D. (1934). La Ferrassie. Préhistoire, 3, 1-92.

Pika, S., \& Mitani, J. (2006). Referential gestural communication in wild chimpanzees (Pan troglodytes). Current Biology, 16(6).

Spoor, F., Leakey, M. G., Gathogo, P. N., Brown, F. H., Antn, S. C., McDougal, I., Kiarie, C., Manthi, F. K., \& Leakey, L. N. (2007). Implications of new early Homo fossils from Ileret, east of Lake Turkana, Kenya. Nature, 448, 688-691.

Sterelny, K. (2008). What is Behavioural Modernity? Paper for the Nicod Lecture, http://www.institutnicod.org/Sterelny-WhatisBehaviouralMordernity.pdf.

Texier, P.-J., Porraz, G., Parkington, J., Rigaud, J.-P., Poggenpoel, C., Miller, C., Tribolo, C., Cartwright, C., Coudenneau, A., Klein, R., Steele, T., \& Verna, C. (2010). A howiesons poort tradition of engraving ostrich eggshell containers dated to 60,000 years ago at diepkloof rock shelter, south africa. Proceedings of the National Academy of Sciences, 107(14), 6180-6185. 
Tobias, P. V. (1998). Evidence for the early beginnings of spoken language. Cambridge Archaeological Journal, 8(1), 72-78.

Tryon, C. A., \& Faith, J. T. (2013). Variability in the Middle Stone Age of Eastern Africa. Current Anthropology, 54(S8), S234-S254.

Wadley, L. (2001). A general view and a South African perspective from Rose Cottage Cave. Cambridge Archaeological Journal, 11(2), 201-221.

Wadley, L., Williamson, B., \& Lombard, M. (2004). Ochre in hafting in Middle Stone Age southern Africa: a practical role. Antiquity, 78, 661-675.

Watanabe, S. (2010). Pigeons can discriminate good and bad paintings by children. Animal Cognition, 13(1), 75-85.

Waters, M. R., Forman, S. L., \& Pierson, J. M. (1997). Diring Yuriakh: A Lower Paleolithic site in Central Siberia. Science, 275, 1281-1284.

Whitley, J. (2003). Archaeology in Greece 2003-2004. Archaeological Reports, 50, 1-92.

Zilhão, J., Angelucci, D. E., Badal-García, E., d'Errico, F., Daniel, F., Dayet, L., Douka, K., Higham, T. F. G., Martínez-Sánchez, M. J., Montes-Bernárdez, R., Murcia-Mascarós, S., Pérez-Sirvent, C., Roldán-García, C., Vanhaeren, M., Villaverde, V., Wood, R., \& Zapata, J. (2010). Symbolic use of marine shells and mineral pigments by Iberian Neandertals. Proceedings of the National Academy of Sciences, 107(3), 1023-1028. 